\title{
Efeito do extrato aquoso e etanólico do angico preto sobre larvas de Rhipicephalus (Boophilus) microplus
}

[The effect of aqueous and ethanolic extracts from the angico Preto about larvae of Rhipicephalus (Boophilus) microplus]

\author{
M.L. Silva Filho ${ }^{1}$, L.B. Silva ${ }^{1 *}$, R.M. Fernandes ${ }^{1}$, G.S. Lopes $^{2}$ \\ ${ }^{1}$ Universidade Federal do Piauí - UFPI - Bom Jesus, PI \\ ${ }^{2}$ Aluna de pós-graduação - Universidade Federal do Piauí - UFPI - Bom Jesus, PI
}

\section{RESUMO}

Rhipicephalus (Boophilus) microplus representa um grande problema na bovinocultura e o uso de acaricidas é a medida de controle profilático e terapêutico mais comum contra esses ectoparasitos. Os principais problemas relacionados com essa prática dizem respeito ao desenvolvimento de linhagens resistentes de carrapatos. Assim, objetivou-se determinar o efeito de extratos da casca de Anadenanthera macrocarpa sobre as larvas de $R$. (B.) microplus, obtidas de um pool de ovos, acondicionadas em tubo de polietileno. De acordo com os resultados, o extrato aquoso na concentração de $8,26 \mathrm{mg} \cdot \mathrm{mL}^{-1}$ causou $85 \%$ de mortalidade nas primeiras 12 horas. Quanto ao extrato etanólico, observou-se maior mortalidade nas concentrações 12,$5 ; 6,25$ e $1,56 \mathrm{mg} \cdot \mathrm{mL}^{-1}$, em torno de $84 \%$, percentuais semelhantes ao amitraz. Os controles negativos não apresentaram mortalidade durante o experimento. Assim, tanto o extrato aquoso como o extrato etanólico apresentaram efeito larvicida, embora o extrato etanólico tenha sido mais eficiente para a espécie, podendo ser uma alternativa no controle desse ectoparasito.

Palavras-chave: acaricida botânico, carrapaticida, ectoparasitas, angico vermelho

\begin{abstract}
Rhipicephalus (Boophilus) microplus represents a major problem in cattle breeding and the use of acaricides is the most common prophylactic and therapeutic control measure against these ectoparasites. The main problems with this practice relate to the development of resistant strains of ticks. Thus, the objective was to determine the effect of bark extracts from Anadenanthera macrocarpa on the larvae of $R$.(B.) microplus, obtained from a pool of eggs packed in a polyethylene tube. According to the results,

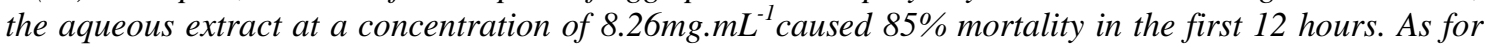
the ethanolic extract, higher mortality of about $84 \%$, a percentage similar to amitraz, was observed at concentrations of $12.5 \mathrm{mg} . \mathrm{mL}^{-1}$, 6.25 $\mathrm{mg} . \mathrm{mL}^{-1}$ and $1.56 \mathrm{mg} . \mathrm{mL}^{-1}$. The negative controls showed no mortality during the experiment. Thus, both the aqueous and ethanolic extracts showed larvicidal activity, although the ethanolic extract has been more efficient and could be an alternative to control this ectoparasite.
\end{abstract}

Keywords: botanical acaricide, tickicide, ectoparasites, angico vermelho

\section{INTRODUÇÃO}

Rhipicephalus (Boophilus) microplus, é considerado um dos mais importantes parasitas de animais, incluindo bovinos, búfalos, cavalos, burros, cabras, cervos, ovelhas, porcos, cães e alguns animais selvagens. Causa impacto

Recebido em 20 de março de 2012

Aceito em 9 de janeiro de 2013

E-mail: lubarbosabio@hotmail.com econômico, reduzindo o ganho de peso e a produção de leite, bem como a transmissão de patógenos como babesiose (Babesia bovis e $B$. bigemina) e anaplasmose (Anaplasma marginale). No Brasil, o grau de infestação desse parasita é responsável por perda econômica significativa, o que representa aproximadamente 2 bilhões de dólares por ano (Grisi et al., 2002; Canales et al., 2008). 
O uso de acaricidas é a principal forma de controle dos carrapatos em rebanho bovino, principalmente por meio de aspersão ou banho de solução aquosa. Os sistemas dorsal, injetável e por bolos gástricos têm sido incrementados nos últimos anos, facilitando o manejo. Novas formas de administração dos produtos vêm sendo desenvolvidas com o objetivo de facilitar o manejo e aumentar a eficiência dos produtos químicos no controle do carrapato (Brito et al., 2011).

O controle químico utilizando acaricidas começou no século XX com os compostos arsenicais e, desde a década de 30 , registram-se casos de resistência a esse princípio ativo. A primeira constatação de resistência de $R$.(B.) microplus aos produtos cloroarsenicais, até então de uso corrente, deve-se aos pesquisadores do Instituto de Pesquisas Veterinárias "Desidério Finamor" do estado do Rio Grande do Sul. Os organoclorados e organofosforados começaram a ser usados no início da década de 50. Vinte anos mais tarde iniciou-se o uso das formamidinas e, logo após, o uso dos piretroides sintéticos, devido à existência de populações de carrapatos resistentes aos princípios ativos (Pereira, 1982). O mercado de substâncias acaricidas no Brasil movimenta cerca de US\$ 960 milhões por ano e constitui $34 \%$ do mercado de produtos veterinários (Sindan, 2010). Para serem registrados, os novos produtos para o controle do carrapato devem apresentar pelo menos $95 \%$ de eficácia, segundo critérios do Ministério da Agricultura, Pecuária e Abastecimento (Mapa) (Brito et al., 2011; Krawczak et al., 2011).

De acordo com Uilenberg (1996), inseticidas e acaricidas provocam certo grau de contaminação ambiental, sendo prejudiciais à vida aquática. Há neles substâncias que têm propriedades físicoquímicas que os tornam ainda mais prejudiciais. Os resíduos e os produtos de degradação dos acaricidas no leite e/ou carne constituem um problema universal e de grande importância na saúde pública. Sua presença interfere na comercialização de produtos de origem animal.

$\mathrm{O}$ uso indiscriminado de acaricidas resulta em vários problemas, como custo do manejo e perda de compostos antes eficientes no controle, devido à seleção de populações resistentes (Rodriguez-Vivas et al., 2011). Além disso, o uso de acaricidas pode promover a seleção de linhagens de carrapatos, o que diminui o período de proteção dos produtos e aumenta o custo de tratamento, que se torna cada vez mais intenso.

Hoje buscam-se métodos alternativos para o controle de ectoparasitas. É importante salientar que as plantas, sobretudo nas regiões tropicais, apresentam grande diversidade de compostos com ação inseticida e/ou acaricida, os quais podem ser utilizados como extratos vegetais, ou como produtos comerciais ou semicomerciais (Mordue e Blackwell, 1993), produtos estes oriundos da coevolução organismo/plantas. Esses produtos naturais também podem ser usados como modelos para a síntese de acaricidas sintéticos com características desejáveis, como maior eficiência, biodegradação e menor toxicidade a organismos não alvos (Hedin et al.,1994; Haq et al., 2004).

O extrato de uma determinada planta pode conter milhares de compostos, oriundos do metabolismo secundário, assim o isolamento de substâncias com potencial inseticida/acaricida, guiado por bioensaios, é a melhor forma para se descobrir fitotoxinas naturais, importantes no controle de pragas. Trabalhos têm demonstrado que os óleos essenciais das plantas apresentam atividade inseticida, podendo ser repelente, ovicida, larvicida, além de inibirem a alimentação, o crescimento e a oviposição (Ho et al., 1996; Regnault-Roger, 1997; Papachristos et al., 2004; Tapondjou et al., 2005; Salem et al., 2007; Stamopoulos et al., 2007; Rajendran e Sriranjini, 2008). Muitos dos ingredientes ativos presentes nos óleos são metabólitos secundários secretados pelas plantas na defesa química contra artrópodes, patógenos e microrganismos (Regnault-Roger, 1997; Rajendran e Sriranjini, 2008). Várias famílias de plantas têm sido extensivamente pesquisadas em relação à sua atividade biológica (Vieira et al., 2001; Moreira et al., 2007; Rosell et al., 2008; Rajendran e Sriranjini, 2008; Silva et al., 2012).

A planta-alvo no presente estudo é Anadenanthera macrocarpa (Benth) Brenan, pertencente à família Fabaceae e à subfamília Mimosoideae e conhecida popularmente como angico preto, vermelho, amarelo, branco, bravo, do campo, rajado, fava, jacaré, rosa, do mato, arapiraca, brincos de sagui, cambuí ferro, curupaí, guarapiraca, angico de casca, paricá, cebil e angico de curtume (Lorenzi, 1992; 
Carvalho, 1994). São reconhecidas pelo valor nutricional de suas sementes, que são ricas em proteínas, carboidratos e óleo. Os compostos envolvidos na defesa química incluem lectinas, inibidores de protease e amilase, toxinas e metabólitos secundários de baixa massa molecular (Xavier-Filho, 1993). Apesar da diversidade de compostos de defesa, poucos estudos têm sido realizados sobre a toxicidade a ectoparasitas.

Considerando-se o avanço nas pesquisas relacionadas aos acaricidas/inseticidas de origem botânica e as perspectivas para a sua utilização no controle de ectoparasitas, desenvolveu-se este trabalho com o objetivo de avaliar, em condições de laboratório, o efeito acaricida do extrato aquoso e etanólico de $A$. macrocarpa sobre larvas de Rhipicephalus (Boophilus) microplus.

\section{MATERIAL E MÉTODOS}

Os ensaios farmacológicos foram conduzidos no Laboratório Ciências Fisiológicas do Departamento de Morfofisiologia Veterinária do Centro de Ciências Agrárias da Universidade Federal do Piauí.

As cascas de A. macrocarpa foram coletadas no município de Angical-PI, no período de fevereiro/2006, identificadas e depositadas no "Herbário Graziela Barroso"/UFPI, exsicata n²1.643/TEPB. A casca da planta, após ser cortada em pedaços menores, foi submetida à secagem em uma estufa de circulação de ar forçada durante três dias, a uma temperatura máxima de $45^{\circ} \mathrm{C}$. Após completa secagem, o material foi triturado em moinho e acondicionado em frasco de vidro hermeticamente fechado.

O extrato aquoso (EA) da A. macrocarpa foi preparado com $60 \mathrm{~g}$ da matéria vegetal para $600 \mathrm{~mL}$ de água destilada, seguido de cocção por dois minutos. Após filtração, determinou-se o peso seco do extrato e retiraram-se três alíquotas de $1 \mathrm{~mL}$ da solução acondicionadas em frascos, os quais foram colocados em estufa com circulação forçada de ar até obtenção de peso constante. A massa média obtida referente a $1 \mathrm{~mL}$ foi relacionada ao respectivo volume total e correspondeu à concentração final de $8,26 \mathrm{mg} \cdot \mathrm{mL}^{-1}$.
O extrato etanólico (EE) foi obtido mediante maceração da matéria vegetal a frio, após quatro extrações sucessivas em intervalos de cinco dias. Posteriormente, foi filtrado e colocado em evaporador rotativo a vácuo, à temperatura de $50^{\circ} \mathrm{C}$, sob pressão de 500 a $750 \mathrm{mmHg}$. O extrato foi congelado em nitrogênio líquido e, em seguida, liofilizado. Depois disso, pesaram-se $2,5 \mathrm{~g}$ do extrato, o qual foi diluído em $25 \mathrm{~mL}$ de dimetilsulfóxido e $175 \mathrm{~mL}$ de água destilada, obtendo-se a concentração de $12,5 \mathrm{mg} \cdot \mathrm{mL}^{-1}$.

As teleóginas de R.(B.) microplus foram coletadas em fazendas localizadas na zona rural de Teresina, PI, situada na região Nordeste do Brasil, latitude e longitude $05^{\circ} 05^{\prime} 21^{\prime}$ ' e $42^{\circ} 48^{\prime}$ $07^{\prime}$, W, respectivamente. A temperatura média é da ordem de $28,8^{\circ} \mathrm{C}$, e a precipitação pluviométrica de $1360 \mathrm{~mm}$ na média anual (Sudene, 1990). As fêmeas ingurgitadas foram coletadas de hospedeiros que não tinham sido expostos a carrapaticida químico a no mínimo 90 dias. Posteriormente, foram divididas em grupos de 10 e pesadas em balança de precisão $(0,0001 \mathrm{~g})$. Ao microscópio esteroscópico, verificou-se ausência de mutilações e de má formação nas fêmeas selecionadas. $\mathrm{Na}$ sequência, foram lavadas em água destilada, secas em papel-toalha e individualizadas para realizarem a oviposição. Das oviposturas constituiu-se um pool de ovos, os quais foram acondicionados em tubo, identificados e vedados com algodão hidrófilo e umedecido, que manteve a umidade no interior dos tubos, até o início dos testes.

Utilizaram-se o extrato aquoso na concentração de 8,$26 ; 4,13 ; 2,06 ; 1,03 ; 0,51 \mathrm{mg} \cdot \mathrm{mL}^{-1}$ e o etanólico na concentração de 12,$5 ; 6,25 ; 3,12$; 1,$56 ; 0,78 \mathrm{mg} \cdot \mathrm{mL}^{-1}$, tendo como controle negativo a água destilada e o dimetilsulfóxido e como controle positivo o amitraz $0,25 \mathrm{mg} \cdot \mathrm{mL}^{-1}$ (dosagem recomendada para bovinos). As larvas, ao saírem do tubo, foram coletadas com um pincel $\mathrm{n}^{\circ} 4$ e imediatamente imersas nas placas de Petri contendo as soluções testes, por 90s e, em seguida, colocadas sobre o centro do papel- filtro do dispositivo de contenção para ensaios com acaricidas, afastadas umas das outras para facilitar sua observação. Colocaramse 20 larvas, tratadas por dispositivo construído a partir de placa de Petri descartável $(9,4 \mathrm{~cm}$ x $1,5 \mathrm{~cm})$, papel-filtro quantitativo $(9 \mathrm{~cm}$ de diâmetro) e parafina. O papel-filtro serviu como 
piso para as larvas e para retirar o excesso de solução. Foi colocado sobre a face interna da tampa da placa de Petri, que funcionou como base do dispositivo. A placa foi lacrada colocando-se entre as suas bordas parafina em fusão. Para cada concentração, foram utilizados 10 dispositivos (10 repetições), bem como para os grupos-controle. Os dispositivos foram mantidos à temperatura e umidade relativa ambiente. Para se observar a interação entre as larvas e as soluções, os dispositivos foram levados ao microscópio estereoscópio nos tempos seis, 12, 18 e 24 horas após a imersão, e, com o auxílio desse aparelho, registrou-se, em cada horário, a mortalidade.

Para possibilitar a comparação dos resultados com os de outros pesquisadores, foram utilizadas nos bioensaios larvas com 14 a 21 dias, e, para efeito de cálculo de mortalidade, larvas sem capacidade locomotora foram consideradas mortas (FAO, 1995).

Para verificar a influência da variável concentração, na eficiência larvicida, foi aplicado o teste de Duncan, a um nível de $95 \%$ de probabilidade. A eficiência dos tratamentos foi interpretada de acordo com o estabelecido pela Organização Mundial de Saúde, em que a mortalidade média igual ou superior a $80 \%$ configura status de susceptível ao vetor, e abaixo de $80 \%$, status de resistência (WHO, 1970; 1992), e pelo Ministério da Agricultura, que preconiza para registro do acaricida mortalidade mínima de $95 \%$ dos ixodídeos na dosagem recomendada (Brasil, 1990).

\section{RESULTADOS}

O peso seco médio obtido para o extrato aquoso (EA) e o extrato etanólico (EE) foi de 8,26mg.mL ${ }^{-1}$ e $12,5 \mathrm{mg} \cdot \mathrm{mL}^{-1}$, respectivamente.

Os resultados obtidos com o extrato aquoso e o etanólico da planta A. macrocarpa estão listados na Tab. 1. A eficácia do tratamento corresponde aos percentuais médios de mortalidade das larvas de R.(B.) microplus.

Tabela 1. Ação larvicida de diferentes concentrações do extrato aquoso e etanólico de A. macrocarpa sobre R.(B.) microplus, observadas durante $24 \mathrm{~h}(\mathrm{n}=20)$

\begin{tabular}{lccccccc}
\hline \multirow{2}{*}{ Extratos } & $\begin{array}{c}\text { Concent. } \\
\left(\mathrm{mg} \cdot \mathrm{mL}^{-1}\right)\end{array}$ & $\begin{array}{c}\text { Morte } \\
6 \mathrm{~h}\end{array}$ & $\begin{array}{c}\text { Morte } \\
12 \mathrm{~h}\end{array}$ & $\begin{array}{c}\text { Morte } \\
18 \mathrm{~h}\end{array}$ & $\begin{array}{c}\text { Morte } \\
24 \mathrm{~h}\end{array}$ & $\begin{array}{c}\text { Total de } \\
\text { mortes }\end{array}$ & Eficiência \\
\hline Extrato aquoso & 0,51 & $1,4 \mathrm{~cd}$ & $1,6 \mathrm{~d}$ & $3,1 \mathrm{e}$ & $5,9 \mathrm{bc}$ & $12,0 \mathrm{e}$ & $60,5 \%$ \\
& 1,03 & $1,6 \mathrm{~cd}$ & $2,7 \mathrm{bcd}$ & $3,4 \mathrm{cde}$ & $6,2 \mathrm{bc}$ & $13,9 \mathrm{~d}$ & $69,5 \%$ \\
& 2,06 & $1,0 \mathrm{de}$ & $1,9 \mathrm{~cd}$ & $4,6 \mathrm{a}$ & $7,2 \mathrm{ab}$ & $14,7 \mathrm{~cd}$ & $73,5 \%$ \\
& 4,13 & $0,0 \mathrm{e}$ & $2,5 \mathrm{bcd}$ & $4,2 \mathrm{abcd}$ & $7,8 \mathrm{a}$ & $14,5 \mathrm{~d}$ & $72,5 \%$ \\
& 8,26 & $3,4 \mathrm{~b}$ & $3,6 \mathrm{~b}$ & $3,5 \mathrm{bcde}$ & $6,3 \mathrm{bc}$ & $16,8 \mathrm{~b}$ & $84,0 \%$ \\
\hline Extrato etanólico & 0,78 & $3,1 \mathrm{~b}$ & $3,1 \mathrm{~b}$ & $3,3 \mathrm{de}$ & $5,10 \mathrm{c}$ & $14,6 \mathrm{~cd}$ & $73,0 \%$ \\
& 1,56 & $2,5 \mathrm{bc}$ & $3,3 \mathrm{~b}$ & $4,0 \mathrm{abcde}$ & $5,40 \mathrm{c}$ & $15,2 \mathrm{bcd}$ & $76,0 \%$ \\
& 3,12 & $2,4 \mathrm{bc}$ & $2,5 \mathrm{bcd}$ & $4,5 \mathrm{ab}$ & $5,50 \mathrm{c}$ & $14,9 \mathrm{~cd}$ & $74,5 \%$ \\
& 6,25 & $2,3 \mathrm{bc}$ & $3,0 \mathrm{bc}$ & $4,2 \mathrm{abcd}$ & $6,00 \mathrm{bc}$ & $15,5 \mathrm{bcd}$ & $77,5 \%$ \\
& 12,5 & $2,9 \mathrm{~b}$ & $3,4 \mathrm{~b}$ & $4,4 \mathrm{abc}$ & $5,70 \mathrm{c}$ & $16,4 \mathrm{bc}$ & $82,0 \%$ \\
\hline Água destilada & - & $0,0 \mathrm{e}$ & $0,0 \mathrm{e}$ & $0,0 \mathrm{f}$ & $0,0 \mathrm{e}$ & $0,0 \mathrm{~g}$ & $0,0 \%$ \\
\hline Dimetilsulfóxido & 12,5 & $0,0 \mathrm{e}$ & $0,3 \mathrm{e}$ & $0,7 \mathrm{f}$ & $1,3 \mathrm{~d}$ & $2,3 \mathrm{f}$ & $2,3 \%$ \\
\hline Amitraz & 0,25 & $11,00 \mathrm{a}$ & $9,00 \mathrm{a}$ & $0,00 \mathrm{f}$ & $0,00 \mathrm{de}$ & $20,00 \mathrm{a}$ & $100 \%$ \\
\hline
\end{tabular}

Médias seguidas de mesma letra na mesma coluna não diferem entre si pelo teste de Duncan a 5\% de significância.

O percentual de mortalidade foi maior nos bioensaios com o EE de A. macrocarpa, quando comparado com o carrapaticida estudado amitraz $\left(0,25 \mathrm{mg} \cdot \mathrm{mL}^{-1}\right)$, o qual causou $100 \%$ de mortalidade após 18 horas (Tab. 1). A porcentagem de mortalidade foi de $82,0 \%$; $77,5 \% ; 74,5 \% ; 76,0 \%$ e $73,0 \%$, respectivamente, nas concentrações de 12,$5 ; 6,25 ; 3,13 ; 1,56 \mathrm{e}$ $0,78 \mathrm{mg} \cdot \mathrm{mL}^{-1}$, quando as larvas foram tratadas com o extrato etanólico. Foi registrado maior percentual de mortalidade nas concentrações 8,26mg.mL $\mathrm{m}^{-1}$ e $12,5 \mathrm{mg} \cdot \mathrm{mL}^{-1}$ dos extratos aquoso e etanólico, respectivamente, após a $12^{\mathrm{a}} \mathrm{h}$ de observação. A mortalidade aumentou em função da concentração e do tempo de exposição aos resíduos dos extratos etanólico e aquoso de $A$. macrocarpa. 


\section{DISCUSSÃO}

Nas últimas décadas, extratos de plantas têm sido amplamente utilizados contra ectoparasitas, pois possuem maior seletividade e causam menor dano a organismos não alvos e são reconhecidamente mais específicos. Alguns extratos de plantas ou fitoquímicos são mais efetivos contra organismos resistentes a diferentes compostos inseticidas e/ou acaricidas, provavelmente por apresentarem diferentes mecanismos de ação, relacionado ao fato de que no extrato da planta estão presentes vários compostos responsáveis pela ação carrapaticida (Clemente et al., 2007; Krawczak et al., 2011).

$\mathrm{O}$ efeito tóxico do material vegetal pode ser oriundo dos odores produzidos após a maceração dos constituintes celulares, que repelem ou prejudicam as larvas, afetando o desenvolvimento para o estágio adulto e a consequente morte. É importante a investigação do extrato bruto, etanólico e aquoso, pois algumas plantas possuem mais de um constituinte químico, como princípio ativo, responsável pela atividade biológica, ou seja, atividade acaricida. Com o fracionamento desses extratos, observa-se redução ou inativação da atividade biológica de alguns constituintes químicos (Türkmen Erol, 2009).

Este estudo foi conduzido para avaliar os extratos aquoso e etanólico do caule de $A$. macrocarpa sobre a mortalidade das larvas de $R$.(B.) microplus, e constitui o primeiro registro para a atividade acaricida de A. macrocarpa. Os extratos etanólico $\left(12,5 \mathrm{mg} \cdot \mathrm{mL}^{-1}\right)$ e aquoso (8,26mg. $\left.\mathrm{mL}^{-1}\right)$ de A. macrocarpa causaram mortalidade superior a $80 \%$, semelhantemente aos resultados obtidos por outros autores, que investigaram a atividade carrapaticida do extrato bruto de diferentes plantas, como Pires (2006). Este relatou que a mortalidade das larvas de $R$.(B.) microplus e $R$. sanguineus, observada após $24 \mathrm{~h}$, foi de $100 \%$, nas concentrações de 8,$6 ; 4,3$; 2,$15 ; 1,07$ e $0,54 \mathrm{mg}$. $\mathrm{mL}^{-1}$ do extrato aquoso de Simarouba versicolor e de $100 \%$, após seis horas de observação, nas diferentes concentrações do extrato etanólico. Chagas et al. (2002a) obtiveram resultados promissores ao testarem formulações elaboradas com óleos essenciais de três espécies de Eucalyptus sp. (Myrtaceae) contra R.(B.) microplus. Eles constataram $100 \%$ de mortalidade larval quando exposto a $10 \%$
( $\approx 100.000 \mathrm{ppm})$ de concentração da fórmula à base de E. staigeriana e E. citriodora e $20 \%$ de E. globulus. Os mesmos autores confirmam a maior eficácia de Copaifera reticulata como um acaricida botânico, o qual causou $99 \%$ de mortalidade larval de R.(B.)microplus nas concentrações $(3491 \mathrm{ppm} \approx 0.35 \%)$ inferiores às dos eucaliptos (10\% e $20 \%$ ), e Fernandes et al. (2007) verificaram que o extrato de Copaifera reticulata causou $99 \%$ de mortalidade para as larvas de R.(B.) microplus, na concentração de $3491 \mathrm{ppm}$.

Geralmente é relatada a atividade biológica das folhas, por estas serem o material mais abundante nas plantas e regenerarem em um curto período de tempo. Porém, Lyndon et al. (1999) verificaram o potencial acaricida do extrato das raiz de $P$. alliacea, o qual causou mortalidade moderada, $59,6 \%$, em relação ao extrato das folhas, $95,7 \%$, e do caule, $99,2 \%$. O extrato do caule de $O$. sanctum causou $88,9 \%$ de mortalidade para as larvas de R.(B.) microplus, segundo Chungsamarnyart et al. (1991). RosadoAguilar et al. (2010) também verificaram alta eficiência acaricida para o extrato do caule de Diospyros anisandra (98,8\%), Bursera simaruba (99,1\%), Bursera simaruba (99,5\%). Tais resultados foram semelhantes aos obtidos no presente trabalho, entretanto a disponibilidade dessa parte da planta é reduzida e a coleta do material vegetal não deve acarretar dano à flora local.

Com a constatação da atividade acaricida para larvas e adultos, é necessário fracionar, purificar e identificar o(s) composto(s) acaricida(s) para que, posteriormente, esse(s) composto(s) $\operatorname{possa}(\mathrm{m})$ ser utilizado(s) para a síntese de novos produtos acaricidas eficientes no controle de R.(B.) microplus.

Há alguns relatos na literatura para compostos isolados de extratos vegetais, que possuem alta eficiência acaricida, como os obtidos por Prates et al. (1993 e 1998), os quais observaram que $\alpha$-pineno presente nos extratos da grama Melinis minutiflora (Poaceae) tem ação larvicida sobre R.(B.)microplus. Chagas et al. (2002b) verificaram que a (+)-cânfora, após 60 minutos, causou mortalidade de $100 \%$ das larvas de $R$.(B.) microplus, enquanto a (+)-isopinocânfora precisou de 45 minutos de contato. 
É fundamental a redução do uso de produtos químicos, a fim de diminuir o impacto ambiental causado pelo acúmulo de compostos carrapaticidas/inseticidas no ambiente e nas cadeias alimentares. Tal redução pode ainda contribuir para a elaboração de uma nova estratégia de controle, pois os acaricidas, como fipronil, cipermetrina e deltametrina, têm sido os principais grupos químicos utilizados no controle aos carrapatos. No Brasil, estudos para monitoramento da suscetibilidade dos carrapatos aos acaricidas, bem como para sua utilização correta, tornam-se necessários e urgentes, uma vez que diversos deles estão sendo administrados indiscriminadamente, sob formas e dosagens variadas, nos animais e nos ambientes infestados, o que gera ineficiência acaricida, prejuízos econômicos aos criadores, intoxicações aos animais e ao homem, e pode levar ao desenvolvimento de cepas resistentes.

A investigação de compostos oriundos de plantas (fracionamento, purificação e identificação dos compostos ativos) que sejam eficientes no controle de ectoparasitos é importante no sentido de se analisarem compostos ativos com diferentes mecanismos de ação, a fim de ampliar as estratégias de controle e minimizar a seleção de populações resistentes. Acaricidas obtidos de extratos de plantas podem ter aplicações práticas, na proteção de grupos naturais, os quais podem ajudar pequenos produtores. $\mathrm{O}$ uso da flora nativa é promissor em decorrência da rápida degradação dos constituintes ativos, após a maceração, o que reduz a presença de resíduos sobre organismos benéficos.

Recomendam-se estudos similares, que usem separadamente outras partes da planta, o fracionamento desses extratos e testes sobre outras fases de vida do carrapato, diferentes organismos e, ainda, a análise dos resíduos deixados no ambiente, para, com base nesses dados, sugerir sua posterior utilização prática.

\section{CONCLUSÃO}

O extrato aquoso de $A$. macrocarpa provocou mortalidade de $84 \%$ em larvas de R.(B.) microplus, e o extrato etanólico de $A$. macrocarpa acarretou mortalidade de $82 \%$ em larvas de R.(B.) microplus. É o primeiro registro para a atividade carrapaticida do extrato bruto de A. macrocarpa, devendo ser realizados estudos para elucidar os compostos responsáveis e o mecanismo de ação.

\section{REFERÊNCIAS}

BRASIL. Ministério da Agricultura. Portaria $\mathrm{n}^{\circ} 90$ de 4 de dezembro de 1989. Normas para produção e utilização de produtos antiparasitários. Diário Oficial, 22 jan., seção 1, coluna. 2, 1990.

BRITO, L.G.; BARBIERI, F.S.; ROCHA, R.B. et al. Evaluation of the Efficacy of Acaricides Used to Control the Cattle Tick, Rhipicephalus microplus, in Dairy Herds Raised in the Brazilian Southwestern Amazon. Vet. Med. Int., v.2011, p.1-6, 2011.

CANALES, M.; DE LA LASTRA, J.M.P.; NARANJO, V. et al. Expression of recombinant Rhipicephalus (Boophilus) microplus, $R$. annulatus and $R$. decoloratus $\mathrm{Bm} 86$ orthologs as secreted proteins in Pichia pastoris. BMC Biotechnol., v.8, p.8-14, 2008.

CARVALHO, P.E.R. Espécies florestais brasileiras. Recomendações Silviculturais, potencialidades e uso da madeira. Brasília:EMBRAPA-CNPF, 1994. 640p.

CHAGAS, A.C.S.; PASSOS, W.M.; PRATES, H.T. Efeito acaricida de Eucalyptus em Boophilus microplus: óleos essenciais e concentrados emulsionáveis. Braz, J. Vet. Res. Anim. Sci., v.3, p.247-53, 2002a.

CHAGAS, A.C.S.; PRATES, H.T.; LEITE, R.C. Ação larvicida de derivados arilsulfonílicos da (+)-cânfora e da (+)-isopinocânfona, em Boophilus microplus. Arq. Bras. Med. Vet. Zootec., v.54, p.462-467, 2002b.

CHUNGSAMARNYART, N.; JIWAJINDA S.; JANSAWAN, W. Larvicidal effect of plant crude-extracts on the tropical cattle tick ( $B$. microplus). J. Nature Sci. Supplement, v.25, p.80-89, 1991.

CLEMENTE, M.A.; GOMES, F.T.; SCOTTON, A.C.B.S. et al. Avaliação do Potencial de Plantas Medicinais no Controle de Boophilus microplus (Acari: Ixodidae). Rev. Bras. Biocienc., v.5, p.516-518, 2007.

FAO. Acaricide resistance test kit. Instructions for use. 11. Ed. Berlin: World Acaricide Resistance Reference Centre (WARRC), 1995. 9p. 
FERNANDES, F.F.; FREITAS, E.P.S. Acaricidal activity of an oleoresinous extract from Copaifera reticulata (Leguminosae: Caesalpinioideae) against larvae of the southern cattle tick, Rhipicephalus (Boophilus) microplus (Acari: Ixodidae). Vet. Parasitol., v.147, p.150$154,2007$.

FERNANDES, F.F.; FREITAS, E.P.S.; COSTA, A.C.; SILVA, I.G. Larvicidal potential of Sapindus saponaria to control the cattle tick Boophilus microplus. Pesq. Agrop. Bras., v.40, p.1243-1245, 2005.

GRISI, L.; MASSARD, C.L.; MOYA BORJA, G.E.; PEREIRA, J.B. Impacto econômico das principais ectoparasitoses em bovinos no Brasil. Hora Vet., v.125, p.8-10, 2002.

HAQ, S.K.; ATIF, S.M.; KHAN, R.H. Protein proteinase inhibitor genes in combat against insects, pests, and pathogens: natural and engineered phytoprotection. Arch. Biochemistry and Biophysics, v.431, p.145-159, 2004.

HEDIN, P.A.; MENN, J.J.; HOLLINGWORTH, R.M. Natural and engineered pest management agents. Washington: American Chemical Society, 1994. 552p.

HO, S.H.; KOH, L.; MA, Y. et al. The oil garlic, Allium sativum L.(Amaryllidaceae), as a potential grain protectant against Tribolium castaneum (Herbst) and Sitophilus zeamais Motsch. Postharvest Biol. Technol.,v.9, p.41-48, 1996.

KRAWCZAK, F.S.; BUZATTI, A.; PIVOTO, F.L. et al. Atividade acaricida de extratos de folhas de Sambucus australis Schltdl (Caprifoliaceae) a 2\% sobre teleóginas de Rhipicephalus (Boophilus) microplus. Cienc. Rural, v.41, p.2159-2163, 2011.

LORENZI, H. Árvores brasileiras. Manual de Identificação e cultivo de plantas arbóreas nativas do Brasil. Nova Odessa: Plantarum, 1992. 352p.

LYNDON, J.; LAWRENCE, A.D.; EARLE. V.R. An Insecticidal and Acaricidal Polysulfide Metabolite from the Roots of Petiveria alliacea. Pesticide Sci., v.50, p.228-232, 1999.

MORDUE, A.J.; BLACKWELL, A. Azadirachtin: an update . J. Insect Physiol., v.39, p.903-924, 1993.
MOREIRA, M.D.; PICANÇO, M.C.; BARBOSA, L.C.A. et al. Compounds from Ageratum conyzoides: isolation, structural elucidation and insecticidal activity. Pest Manag. Sci., v.63, p.615-621. 2007.

PAPACHRISTOS, D.; STAMOPOULOS, D.C. Fumigant toxicity of three essential oils on the eggs of Acanthoscelides obtectus (Say) (Coleoptera: Bruchidae). J. Stored Prod. Res., v.40, p.517-525, 2004.

PEREIRA, M.C. Boophilus microplus: revisão taxonômica e morfológica. Rio de Janeiro: Quimio Divisão Veterinária. 1982. 167p.

PIRES, J.E.P. Efeito dos extratos aquoso $e$ etanólico de planta Simarouba versicolor, St. Hill Sobre larvas e teleóginas de carrapatos Boophilus microplus, Canestrini, $1887 e$ Rhipicephalus sanguineus, Latreille, 1806. 49f. 2006. Dissertação (Mestrado em ciência animal) - Universidade Federal do Piauí, Teresina, PI.

PRATES, H.T.; LEITE, R.C.; CRAVEIRO, A.A. Identification of some chemical components of the essential oil from molasses grass (Melinis minutiflora Beauv.) and their activity against catle-tick (Boophilus microplus). J. Brazilian Chemical Soc., v.9, p.193-197,1998.

PRATES, H.T.; OLIVEIRA, A.B.; LEITE, R.C.; CRAVEIRO, A.A. Atividade carrapaticida e composição química do óleo essencial do capimgordura. Pesq. Agrop. Bras., v.28, p.621-625, 1993.

RAJENDRAN, S.; SRIRANJINI, V. Plant products as fumigants for stored-product insect control. J. Stored Prod. Res., v.44, p.126-135, 2008.

REGNAULT-ROGER, C. The potential of botanical essential oils for insect pest control. Inter. J. Pest Management, v.2, p.25-34, 1997.

RODRIGUEZ-VIVAS, R.I.; TREES, A.J.; ROSADO-AGUILAR, J.A. et al. Evolution of acaricide resistance: Phenotypic and genotypic changes in field populations of Rhipicephalus (Boophilus) microplus in response to pyrethroid selection pressure. Inter. J. Parasitol., v.41, p.895-903, 2011. 
ROSADO-AGUILAR, J.A.; AGUILARCABALLERO, A.J.; RODRÍGUEZ-VIVAS, R.I. et al. Screening of the acaricidal efficacy of phytochemical extracts on the cattle tick Rhipicephalus (Boophilus) microplus (Acari: ixodidae) by larval immersion test. Trop. and Subtrop. Agroecosystems, v.12, p.417-422, 2010.

ROSELL, G.; QUERO, C.; COLL, J.; GUERRERO, A. Biorational insecticides in pest management. J. Pesticide Sci., v.33, p.103-121, 2008.

SALEM, S.A.; EBOU-ELA, R.G.; MATTER, M.M.; EL-KHOLY, M.Y. Entomocidal effect of Brassica napus extracts on two store pests, Sitophilus oryzae (L.) and Rhizopertha dominica (Fab.) (Coleoptera). J. Appl. Sci. Res., v.3, p.317322, 2007.

SILVA, L.B.; TORRES, E.B.; SILVA, K.F. et al. Toxicity of ethanolic extract of Croton heliotropiifolius in weevil populations of stored maize grains. J. Entomology, v.6, p.413-421, 2012.

SINDAN. Sindicato Nacional da Indústria de produtos para Saúde Animal, 2010. Mercado veterinário por classe terapêutica e espécie animal, 2009. Disponível em: <http://www. sindan.org.br/sd/sindan/index.html $>$. Acessado em: 12 jul. 2010

STAMOPOULOS, D.C.; DAMOS, P.; KARAGIANIDOU, G. Bioactivity of five monoterpenoid vapours to Tribolium castaneum (du Val) (Coleoptera: Tenebrionidae). J. Stored Prod. Res., v.43, p.571-577, 2007.
SUDENE. Superintendência do Desenvolvimento do Nordeste. Dados pluviométricos mensais do nordeste: Estado do Piauí. Recife: SUDENE, p.75-77, 1990 .

TAPONDJOU, A.L.; ADLEN, C.; FONTEM, D.A. et al. Bioactivities of cymol and essential oils of Cupressus sempervirens and Eucalyptus saligna against Sitophilus zeamais Motschulsky and Tribolium castaneum du Val. J. Stored Prod. Res., v.41, p.91-102, 2005.

TÜRKMEN EROL, N.; SARI, F.; POLAT, G.; VELIOGLU, Y.S. Antioxidant and Antibacterial Activities of Various Extracts and Fractions of Fresh Tea Leaves and Green Tea. Tarim Bilimleri Dergisi, Ankara Üniversitesi Ziraat Fakültesi. v.15, p.371-378, 2009.

UILENBERG, G. Integrated control of tropical animal parasitoses. Trop. Anim. Health Product., v.28, p.257-265, 1996.

VIEIRA, P.C.; MAFEZOLI, J.; BIAVATTI, M.W. Inseticidas de Origem Vegetal. In: FERREIRA, J.T.B.; CORRÊA, A.G.; VIEIRA, P.C. (Eds.). Produtos naturais no controle de insetos. São Carlos: Editora Universidade de São Carlos, 2001. p.23-45.

WHO - World Health Organization. Doc. TRS/443. Genéve: WHO. 1970.

WHO - World Health Organization. Vector resistance to pesticides. Doc. TRS/818. Genéve: WHO. 1992.

XAVIER-FILHO, J. Sementes e suas defesas contra insetos. Projeto multinacional de biotecnologia e alimentos. Organização dos Estados Americanos. Edições UFC, Fortaleza, 1993. 